\title{
Norway Reimagined
}

\section{Popular geopolitics and the Russophone fans of Skam}

\author{
Saara Ratilainen
}

Aleksanteri Institute, University of Helsinki, Finland

\begin{abstract}
In this article, I discuss the geopolitical underpinnings of Russophone fans' response to the Norwegian hit teen series Skam [Shame]. Starting from the wide-spread distribution of Skam through informal horizontal networks, my article highlights the context specificity of fan participation in meaning-making around global television. Employing multimodal discourse analysis to the social media platform VKontakte, I examine how Russophone audiences of global television imagine the country of origin of their object of fandom, and how spatial imaginations embedded in this process contribute to popular geopolitics of Norden - that is, to geopolitical reasoning of narratives and representations of Nordic countries available through popular culture. My analysis shows how Norway and its positioning in the world provides an important symbolic resource for further discussions on identity and belonging. A close examination of mediated transnational cultural exchange through fan communities advances our understanding of the meaning of popular geopolitics in the age of global television.
\end{abstract}

Keywords: popular geopolitics, fandom, Russophone audience, Nordic TV, transcultural communication

\section{Introduction}

Finding success around the world, the Norwegian teen series Skam [Shame $]^{1}$ increasingly contributes to the global image of Norden as a source of innovative, quality television for a global audience (Saunders \& Vessels, 2019). Skam has also become an important part of Norway's national brand and attracted a stream of tourists to visit the set locations and (if lucky) meet the stars of the series in real life. Fans share these encounters online, which further emphasises the idea of interactivity through spatial connectivity as an important ingredient of contemporary television fandom. ${ }^{2}$ Within this highly mediated and cosmopolitan context, Skam has invited fans to participate in popular cultural reflection of issues related to global identity politics and international crisis - such as immigration, LGBTQI+ rights, and religious belonging - that serve as central themes in the individual seasons of the series. These themes constitute important threads in Skam's overlapping storylines that otherwise focus on more conventional teen topics such as love, dating, and parties.

Ratilainen, S. (2020). Norway reimagined: Popular geopolitics and the Russophone fans of Skam. Nordicom Review, 41(Special Issue 1), 139-153. https://doi.org/10.2478/nor-2020-0016 
In this article, I discuss Skam fandom in the framework of spatial imaginations as they are intertwined with representations of identity building, taking into account the widespread global distribution of Skam through informal online networks. I analyse how fans who participate in online discussions make sense of Skam's narrative and character developments by using spatiality as a key symbolic resource, thereby discursively building on a shared understanding of imaginary Norway as the main locus of their affective relationship with the series.

My task in this article is to see how (and also to an extent why) Skam fans outside of Norway (re)imagine its country of origin as the object of their fandom; how, in this process, they take part in producing and reproducing popular geopolitical imaginations, how they make use of and interpret the geopolitical space of Norden, and how these imaginations are interlinked with other - cultural, linguistic, and political - contexts the fans share. In so doing, my article answers Dittmer and Dodds's (2008) call for engaging the study of fan communities with popular geopolitics in order to better understand the role of individual consumers in the construction of geopolitical narratives available through popular culture (see also Dodds, 2008; Dittmer \& Gray, 2010; Glynn \& Cupples, 2015). With my analysis, I aim to demonstrate how popular geopolitics is at work when international television fans discuss issues of identity building and cultural belonging by reconfiguring the spatial and geographical contexts around those issues. More specifically, in this article I aim to answer the following research question:

- What kind of spatial imaginations support and frame the Russophone fan's perception of Skam, and how do these imaginations contribute to popular geopolitics of Norden in the current age of global television?

The discursive space in which my analysis operates comprises the original episodes of Skam and the response from the Russophone audience, ranging from popular memes and comment threads to different forms of more committed and time-consuming creative production, such as fan art and fan fiction. ${ }^{3}$ All these media texts, representations, and reactions are shared horizontally on the online fan forums, which means that the entire Russophone Skam universe exists as a result of user-distribution of international media and user-production of creative responses.

In this context, the fan's perception of Norway is devised in an interactive relationship between the technology-driven online communication environment, transcultural exchange of ideas, and a number of different symbolic resources that inform the fans' sense of spatiality, identity, and connectivity. Therefore, I hypothesise that the complexity of this communicative space allows for a creative reconfiguration of geopolitical spaces by the fan community. A close examination of this type of mediated cultural exchange by grassroots actors advances our understanding of the meaning of popular geopolitics and digital transcultural communication in the age of global television. In this respect, my article reflects on the cultural and geopolitical meanings of Norden and the role of Russophone audiences in producing these meanings.

\section{Data and method}

The focus of my analysis is, in particular, the participation of Russophone fans in conversations evoked by Skam's third and fourth seasons, aired through Norway's Public 
Broadcasting Company NRK's website in 2016-2017. I have collected my data from VKontakte, which is the most popular social media platform among Russophone Internet users and technologically analogous to Facebook. I monitored several informally organised fan profiles devoted to Skam during the research period from 2016-2019 and retrieved several hundred posts on selected topics for closer analysis. All forums monitored for this research exist in the open domain and are accessible even without registering on VKontakte as a user. As one of the profiles centres around LBTQI+ topics that can be sensitive to some users, I have made myself known to the administrators of this forum and am citing anonymously with their permission. For the sake of the semi-private nature of the conversations, I refer to all posts anonymously, often summarising similar, repetitive comments made by a number of individual users. With just a few exceptions, the written texts on the forums are in Russian; therefore, I frame the fan community through the identity of a "Russian-speaking Skam aficionado" who can be fluent in other languages as well, and might be interacting with these forums from outside Russia but is well familiar with the post-Soviet (digital) space as a particular, diasporic discursive realm in which Russia can be used as lingua franca of sorts. ${ }^{4}$

As Danielle Fuller (2019) demonstrates, Skam fandom foregrounds a very specific form of media competence of multimodal reading, that is, engagement with storytelling through layered content and cross-platform media flows. Fan forums are both subsumed into these flows, but, at the same time, they constitute textual storages where the multitude of Skamrelated fragments is brought (and kept) together. In other words, fan forums repeat, reflect, and comment on already existing representations, but in the process, they produce a set of new representations and textual realities. Focusing on this form of textuality, born out of trans-media storytelling, I apply multimodal discourse analysis, that is, the "analysis of language use in conjunction with other semiotic resources which are simultaneously used for the construction of meaning" (O'Halloran, 2004: 1). The object of my analysis is the fans' integrated use of several semiotic resources - mainly language, images, and short videos (especially GIFs) - as they participate in meaning-making processes online. Following the approach to popular cultural texts devised by cultural studies scholars, I read the online forums as sites of "struggle over meaning" and "negotiated engagement" with popular cultural content (see Glynn \& Cupples, 2015: 272), which happens, in this case, through (re)articulation and (re)interpretation of Skam-related representations on social media. Furthermore, I acknowledge the agency of new media technologies in these processes, as I treat online fan profiles as assemblages of both human and non-human actors (e.g., hardware and software, gadgets, apps, screens, etc.) through which they affect not only our everyday communication practices, but also the ontology and epistemology of symbolic production in the digital age (Macgregor Wise, 2017; Manovich, 2002).

I will proceed with first contextualising my case study with a description of Skam fan communities and fan studies in the Russophone context. In the following two passages, I move on to analyse the fan response to the third and fourth seasons of Skam. These seasons are particularly significant from the point of view of popular geopolitics as they tackle themes that are not only related to identity building important to young television audiences, but also political struggles taking place increasingly in an international arena: the global LGBTQI+ rights movement versus the anti-gender backlash, as well as religious and ethnic diversity in the Northern parts of Europe versus rising Islamophobia. I conclude by briefly summarising my most important findings. 


\section{Russophone fans of Skam and transnational fan studies}

The Russophone online Skam fan community is substantial in size. There are several fan profiles on VKontakte with hundreds of thousands of followers: Skam.zone with 329,860 followers; Serial: styd, Skam, Shame with 122,379; and Skam/Styd remeiki with 207,865 . In addition, there are separate spin-off profiles devoted to the couples whose relationships the fans obsessively follow - William and Noora (main characters of the second season) with 25,127 followers, and Isak and Even (the main couple of the third season) with 23,492 - as well as to the most popular single character, Chris, with 31,782 followers (as of April 2019). The accounts are constantly updating, although the number of followers on certain sites is gradually decreasing due to the end of Skam's original Norwegian production in 2017.

The cultural exchange of the Russophone Skam fan community, however, is not limited to the Norway-Russia axis. The fan community follows closely all Skam's remakes produced in different countries. At the time of writing this article, for instance, the fans were sharing, subtitling, and commenting on episodes of the French remake, which followed the German, Spanish, Italian, Dutch, and American versions of Skam. This means that the sequence of remakes enables a dynamic continuation of Skam fandom beyond the original Norwegian production. Sharing and commenting on remakes has also expanded the need for navigating multiple overlapping cultural resources and languages. In consequence, the Russian fan community of Skam appears to be a huge multilingual, cross-cultural, transnational effort of netizen activity.

The Russophone fan community can, thus, be understood from the vantage point of superdiversity of the Internet, that is, continuous "diversification of diversity" of new linguistic and cultural forms through global digital connectivity (Vertovec, 2006: 1). In this type of interconnectivity, translation from one language to another, multimodal communication, and the use of multiple simultaneous cultural resources play an important role. As Varis and Wang (2011) point out, this diversity is, however, controlled through multiple layers of self-, state- and peer-imposed normativity and, they continue to argue, communication in online communities evolves in the "dynamics between freedom, creativity, and normativity" (Varis \& Wang, 2011: 72). In my analysis, I examine how the fans' symbolic production of different spaces is embedded in this dynamic of the Internet's communicative space.

Fan studies has increased relevance across disciplines with the digital turn in communication and the emergence of new modes of participation on online platforms. As Karen Hellekson and Kristina Busse (2014: 15) observe, "fan cultures have moved from being a tolerated or ignored unruly fan response to an important and sought-after audience of engaged readers". Applying fan studies to popular geopolitics will help increase context sensitivity in the analysis of globally circulating popular culture, as reception is tied to, and even "constrained", in the physical (geographical, nation-state, technological) context in which cultural representations and meanings circulate (Dittmer \& Dodds, 2008). Global communication technologies have significantly intensified cultural exchange between different contexts of reception, which consequently has to do with the change in the ways geopolitical narratives are embedded and read in popular culture. For example, Paul Adams notes, "geopolitical discourses now reverberate in a multitude of communication spaces stretched between nations via a range of media", and continues to argue that this type of mediation of geopolitical narratives contributes to "exacerbat- 
ing tensions between national populations with different interests and worldviews but also [to] framing ephemeral supranational communities that dissipate tension" (2007: 2, cited in Dittmer \& Dodds, 2008: 445). In this article, the Russophone online fan community of Skam represents exactly this kind of "ephemeral supranational" collective of cultural exchange, that is, a collective whose organisation and systems of belonging reach beyond the boundaries of state.

Currently, fan studies remain a marginal area in the study of Russophone media and culture. The few fan communities that have been the focus of previous scholarship are studied from the perspective of participatory reading practices and fan fiction (Samutina, 2013, 2016, 2017), online video production (Ratilainen, 2019a), and football subcultures (Glathe, 2016). These studies view fan communities mainly from the perspectives of identity building, cultural belonging, and politics of culture. Unlike previous works, my analysis here illuminates Russophone fandom not merely by looking at the interactions between "global" and "local" forms of cultural organisation, but at those established in a transcultural community, that is, in "a group in which people from many [...] backgrounds find a sense of connection across difference, engaging with each other through a shared interest while negotiating the frictions that result from their social and historical contexts" (Annet, 2014: 6). In transcultural communities, recognising tensions between "Sameness" and the "Other" becomes a central line of engagement. This focus will also help devise a nuanced reading of the popular geopolitics involved in Russophone fans' response to Skam.

\section{Reimagining Nordic queer spaces}

Russia as a geopolitical actor appears in Skam as part of the coming-out story of young Isak in the third season. The LGBTQI+ theme is activated through an embedded ministory of a same-sex great power romance. As Isak cyberstalks his new romantic interest Even, he finds an online video in which Even is talking about his film project at his former school. In the video, Even explains, "the movie is about Captain America and Vladimir Putin who fall in love, but they can't be together because Sarah Palin has bewitched them. Every time they kiss, a cat dies of AIDS". Although this message can sound provocative from the viewpoint of the Russian audience, the Russophone fans on VKontakte do not actively respond to it.

Below the Russian subtitled episode, there are a total of 153 comments, and only 3 are reactions to the Putin reference, none of which receive any response from the community. One of the comments actually asks: "Why isn't anyone talking about Putin?" Why, indeed, isn't anyone talking about Putin, although this fragment can certainly be read as an invitation to apply a Russia-centric great power framework to the further LGBTQI+ related themes in the third season of Skam by the Russophone fans? My short answer is because online fan communities constitute their own interpretive frameworks, which may bypass the most common popular geopolitical imageries represented here by the (dangerous) liaison between a superhero and world leader. Online fan communities, in turn, focus on knowledge sharing productive for collective identity building and affective engagement.

Natalia Samutina (2013) has discussed in detail how Russophone fandom around global popular culture (Harry Potter in her case) is an essentially queer space where 
contesting sexual and gender norms is at the centre of creative engagement with the popular genre of fantasy fiction. She stresses the role of fan fiction as an alternative space of individual freedom and liberation from the restrictions felt strongly elsewhere in society. ${ }^{5}$ Samutina locates sexual transgression and "queering" of gender norms by Russophone fans in the creative space of fans' imagination that reflects a reversed image of Russian state-supported homophobia, relocated in fictional fantasy worlds. These creative processes of sexual transgression and imaginary relocation of different sexual regimes "elsewhere" from Russia is similarly at stake when Russophone fans respond to the third season of Skam. However, the question of sexual geographies becomes foregrounded as these imaginations rely on readily available images of Norwegian society, as well as (Northern) European democracy, that the fans identify at the background of Skam's depiction of the everyday life of its characters.

In fact, the Russophone online Skam fan community came into being during the third season. (That's when Skam broke through globally. An earlier, shorter version of my analysis of the Russophone fan response to the third season of Skam is published in Ratilainen, 2019b.) Both what claims to be the official fan profile ("Skam family") and the popular spin-off profile ("Isak \& Even") were founded on VKontakte, when the third season was into its fourth week in Norway. The first updates on the "Skam family" fan site introduce the new forum as a "friendly community where everyone can respect one another". The community rules of the fan site forbid "destructive criticism" and "religious intolerance, homophobia, heterophobia, racism and sexism". The fans' comments on the love story of Isak and Even, however, range from frustrated and judgmental to positively surprised and nearly ecstatic. Some individual fans are actively negotiating between their personal emotions, attitudes, and even prejudice towards the LGBTQI+ community, which can translate to highly negative and stereotyped expressions, and the overall discursive framework of global Skam fandom, based on acceptance, affection, and identification with the characters.

Those fans who take part in the celebratory reproduction of the Isak-Even romance on the separate spin-off fan site acknowledge the differences between Norwegian and Russian state politics concerning LGBTQI+ rights, as well as the effect the national context has on the surrounding media discourse. The fan page starts with a disclaimer: "The age limit of this forum is $18+$ and the administrators do not take responsibility for people younger than that seeing content on this site". With an even more direct reference to the current Russian legislative framework banning "propaganda of non-traditional sexuality" to minors, the post continues: "All information [...] is provided exclusively for entertainment, not for propaganda purposes". The closing statement of the disclaimer, however, makes a conceptual transition from this mandatory labelling of media content into the realm of Skam's worldview emphasising plurality of identities and ideologies: "Even if you believed in Allah or Jesus, or the evolution theory, or in parallel universes, there is only one thing we know for sure: what is happening right now".

Further, on the forum, the affective engagement with the same-sex relationships is expressed through intensive repetition of the scenes the fans find most striking, for instance through a sequence of screengrabs visually chronicling all kisses between the two male characters. The most impressive romantic encounters between Isak and Even are also reproduced in fan-art images. In fan production, the original storyline blends with popular fan fiction stories circulating across the Internet. Certain fan fictions imagining 
Isak and Even's future together have been established as well-known extensions to the original storyline, to which the fans regularly refer in their communication: Isak and Even will get married and have two children, a boy and a girl.

In some other fan fiction stories and drawings, Isak and Even are portrayed as participating in LGBTQI+ activism, that is, wearing the rainbow symbol and taking part in Pride. These representations relocate Isak and Even from their usual high-school environment to the new context of the global LGBTQI+ rights movement and adult everyday life marked by social status and parenting responsibilities. However, combining the normative value of the nuclear family with LGBTQI+ identities, these images also build on ideas of homonormativity and the "international gay" criticised by many queer theorists for taming the subversive potential of queer representations through patriarchal institutions and neoliberal branding of identities (see Schoonover \& Galt, 2016). Following the ideas of Schoonover and Galt, Russophone fans' perception of Isak and Even can thus be read as a homonormative fairy tale, in which "queer relations represent progress and modernity" (2016: 61), and, when set in transcultural context, they reinforce the conflict of values between the "liberal west" and "other" parts of the world.

These images, vaguely spatialised "elsewhere" from Russia and in the "liberal west", however, co-exist and intertwine with spatial and geographic imaginations anchored more explicitly in Skam's native Norway. For example, as if to emphasise the role of the modern city Oslo as an important eyewitness to the Isak-Even love story, a number of fan art collages reproduce the city views used in the original series between scenes and combine them with their favourite images of the two main characters. By reproducing different versions of these collages, the fans collectively create an imaginary Nordic topography as a shared transnational space of their symbolic work. In this topography, geographical signifiers are affectively juxtaposed with Isak and Even's kissing scenes as if to underscore that a gay romance takes place openly, in a shared city space.

The background location of Oslo in particular receives an idealised, almost mythical meaning through further reproduction of Isak and Even's kisses against images of natural landscapes, which can be read as a metaphor of untamed lust and passion behind the attraction between these two characters. Reshuffling and re-combining well-known images with new ones (for instance, landscapes that are not self-evidently from Norway), emphasises the role of imaginary Norway as a metaphorical space where fans are entitled to reach beyond their immediate symbolic realms. However, the oscillation between different geographies - realistic and metaphorical, city and nature - can be interpreted to mean that there is also something unattainable in this love, something that continues to escape to the domain of the imaginary and metaphorical.

This symbolic work can thus be interpreted as a tension between freedom of expression, provided by transcultural communication online, and normativity of the social realities in which the fans live. This tension activates a discursive struggle for finding expressions for the variety of forms love can take. This interpretation is confirmed by a small conversation between two fans under a picture of Herik Holm (actor playing Even) in the role of a prince in a theatre production he did after Skam. A fan comments, "and Tarjei (Sandvik Moe, the actor playing Isak) is his princess", to which another fan replies, "in Norway it is possible for a prince to have a prince". This small exchange raises the important question of boundaries of discourse: different legal, societal, and historical frameworks have an impact on how imagination works, but the transcultural 
context of television fandom might help some become aware of, reassess, and eventually overcome those boundaries.

Other visual reminders of Norwegian state institutions and national symbols are not prominent in the forum but remain in the background. When national symbols are used by the fans, the message is, however, strong. Norway's Independence Day (17 May) coincides with the International Day against Homophobia, which is not left unnoticed by the Russophone fans: on 17 May 2017, a screenshot of Isak and Even was embedded in a picture of the Norwegian flag. A year later, a different adaptation of the same theme appeared: different coloured T-shirts of the kissing couple formed the colour-scheme of the Norwegian flag. In this representation, the nation-state Norway refers to LGBTQI+ rights and sexual liberation through a metonymic relation.

Overall, these posts published in celebration of Norway's Independence Day, in my view, capture the whole range of geopolitical imaginations (re)produced by the Russophone Skam fan community to frame and interpret the LGBTQI+ theme as an international identity-politics and human-rights issue. First, the use of one of the most sacred national symbols, the flag, pinpoints the intensity and depth of the symbolic meanings the fans ascribe to the image of Isak and Even as a couple. Second, the affirmation by the national symbol of the openness and legitimation of the same-sex-representation can be seen as referring to the current curtailment of a similar symbolic field in the Russian context, which a lot of the Russophone fans presumably share. Third, the celebratory use of the national symbol elevates the picture of Isak and Even as if turning it to an abstraction of love and affection that one can feel simultaneously toward one's home country and loved ones. In summary, the response from the Russophone fans to the third season of Skam illustrates the different ways intimate spaces are geopolitically framed and negotiated in transcultural grass-roots symbolic production.

\section{Othering or familiarising religion}

One of the most important geopolitical narratives of Skam unfolds gradually through the character of Sana. She is part of the "girl squad, the group of five main female characters whom the story follows from the start of their sophomore year of high school until the end of their senior year. Sana is a practicing Muslim, and through her religion, she often represents the moral high ground in relation to the other characters. The function of her character, in general, is to bring up and challenge everyday-level cultural stereotypes about Islam, more particularly about Muslim women in the Norwegian (and perhaps also more broadly, in the Nordic) context. She is shown as having to repeatedly confront and overturn her schoolmates' preconceptions about her religion in conversations in which her friends associate Islam with terrorism and refugee status, and her hijab with women's oppression, which is a typical western stereotype about "veiled" Muslim women (see Naghibi \& O’Malley, 2005). It soon becomes apparent that Sana definitely does not match with any of these stereotypes: she is from a wealthy family, outspoken, and comfortable with her religious values and lifestyle. In the fourth season, she becomes the focal character, which adds depth and complexity to her story. This way, the viewer now gets an opportunity to follow the path of the Skam youngsters towards graduation and adulthood through the eyes of a character who, as a hijab-wearing Muslim woman, represents a multifaceted symbolic field intersecting religion, ethnicity, and womanhood. 
From fandom's point of view, Sana's season is as important as the previous one with Isak and Even. When the trailer of the fourth season was released and its focal character announced, the fans found out that this was going to be the last season. The fans started to mourn the end of their beloved show even before the start of the final season. Even though Sana was not the obvious number-one pick for the lead character among the fans, the hype around the news about Skam's conclusion intensified the fans' devotion and participation in online conversations even further. Some fans were very open about their disappointment, while some others were happy to see that Isak and Even at least continue to appear in kissing scenes (Even was a strong candidate for the lead character of the fourth season in fan-organised polls on social media). Sana's season took a step further in the geopolitical framing of Skam through the theme of ethnic and religious diversity, prejudice against Muslims in Europe, and Sana's struggle to belong to the mainstream Norwegian youth culture with liberal attitudes about drinking and premarital sex.

This makes Sana perhaps the first (female) Muslim lead character in a Nordic television series. Visually and culturally, her character resembles, for instance, the main heroes from Marjane Satrapi's graphic novel Persepolis (2000) and Randa Abdel-Fattah's young adult novel Does My Head Look Big in This? (2005, translated to Russian in 2009). Through these cultural cues, Sana's season thus can be read in the context of a growing number of high-circulation popular cultural texts that in one way or another make Islam and Muslim culture available to broad audiences, simultaneously talking back and commenting on the multifaceted and politically encoded cultural encounters between "western" and "non-western" cultures (see, Naghibi \& O'Malley, 2005: 228).

Sana's overall story in Skam, however, is that of belonging and blending of two apparently different and conflicting cultural contexts. With a number of visual framings, Sana's hijab, for instance, is integrated in the Norwegian youth culture, mainstream youth fashion, and national traditions with distinctively Norwegian symbols. One of the most effective scenes in this respect is the one in which she is shown as wearing her hijab with the national Norwegian women's costume for the Independence Day celebration in the last episodes of the second season. On the level of Skam's temporal structure, the master plot of the entire series - three years of high-school and preparation for graduation by the main characters - is, in the fourth season, re-framed with Ramadan, the Muslims' month of religious fasting. Unlike what would have been expected, the series does not end with a high-school graduation party, but with the celebration of Eid al-Fitr marking the end of Ramadan. This scene gathers all of Skam's key characters together, and the very final frames illustrate a festive speech by Jonas, one of the central male characters, addressed in honour of Sana, and include screenshots of online fan forums where reallife fans affectionately relate with Skam's characters. As a result, the fan community gets the final word, and these last images closing a popular television show anticipate the continuation of Skam through external or extra-canonical texts on online fan forums and in fan fiction.

By Sana's season, Russophone fans had subtitled and shared all episodes of the three previous seasons and established the fan forums on VKontakte as an active and rapidly expanding discussion space. The updates on the general, non-character-specific fan sites were steadily gathering over a hundred comments each and a new forum, Skam.zone, was founded in anticipation of the fourth season. When the fourth season was about to start in Norway, Russophone fans were catching up with the speculations on the new 
main character and the release date in real time. The fourth season was now shared on VKontakte clip-by-clip from the beginning. Despite the attempt from the production team to geo-block NRK's video service, the most eager fans from the Russophone community found a way to watch the original clips through Norwegian applications already before the subtitled versions appeared on VKontakte. Since these fans obviously were not Norwegian speakers, the first Russophone comments on the fourth season were only trying to guess what was going on and what the characters were saying. One comment captures very well the feeling of watching the beloved series from behind the language barrier: "7 minutes of incomprehensible words and super-enjoyment!"

Russophone fans were also actively engaging in conversations about Islam. Overall, these conversations reflect an encounter with a cultural and religious framework with which the majority of fans is not particularly familiar. Islam is mainly understood through the idea of rules and regulations, and more specifically through the question of whether Sana is or is not allowed to take off her hijab, which the fans frequently raise in comment threads. For someone following Sana's story from outside her religious context, the hijab, then, becomes the main signifier of Muslim identity and religious lifestyle. The conversations focusing on Sana's hijab only are in line with the overall fascination of the fans with the appearance of Skam's characters (and actors). The hijab, in this context, associates with women's hair, one of the most important signifiers of femininity and female sexuality in popular culture.

It is also because of the hijab why the fans will never find out what Sana's hair looks like. The fans turn this question into a riddle and a game. The idea of this game is crystallised, for instance, in a meme shared first in the forum's newsfeed and later in the comment threads. The meme is a collage of still images from a popular Russian quiz show portraying the host and a competitor (who looks like a wizard from The Lord of the Rings). The text fragments accompanying the images and conveying a made-up dialogue between the host and the competitor go: "Please, choose a category". To which the next caption answers: "Mysteries of the humankind". The last caption in the collage asks: "What colour is Sana's hair?" Some fans participating in this game-like conversation prompted by Sana's hijab go as far as to post a picture of a different young woman remotely resembling Sana, which they have found on the Internet, claiming that it is a picture of Sana without the hijab.

When the fans address Sana's hijab more seriously, outside the game discourse, they usually discuss the meaning of hijab in Islam and the ways Muslim women wear it in different social contexts. In a similar vein as in the actual series (in conversations between Sana and her friends), these comments also emphasise that to wear a hijab is a Muslim woman's own choice, not something she is forced to do. They also emphasise that devout Muslims will not take off their hijab even "for TV or fans", as some fans wish Sana would do. These comment threads show how, on the fan forum, the religious identity of actress Iman Meskini who plays Sana and the religious identity of her fictional character blend together in the online Skam universe. The religious themes in Skam are thus read and interpreted against Meskini's personal Instagram account, where she shares moments of her life with family and friends. In these types of comments, the participants in the Russophone Skam fan community remind one another time and again to talk respectfully about religion. When one commentator, for instance, asks Sana to "take off that nonsense" (obviously referring to her hijab), several other fans find it of- 
fensive and, in turn, write in their comments that "religion does not do any harm" and that this comment insulted "millions of Muslims".

In terms of geopolitical imaginations, the Russophone fans reflect Skam's religious themes against broader questions of Islam and Muslim communities in Russia and elsewhere. ${ }^{6}$ In the Russophone Skam online universe, overtly Islamophobic discourse is against the rules and thus absent from the comment threads. Sana's religious practice and other religious themes are generally perceived in a very positive light: in the eyes of the fans, religious conviction makes Sana morally superior in relation to other characters, who are not religious, and she is declared "the queen of the series". From the perspective of geographical and geospatial framing, the question of Islam as it appears on the Russophone Skam fan sites is, however, more complex. In one particular comment thread, for instance, a heated conversation starts with a comment claiming that "there are no Muslims in Russia". This idea is in apparent contradiction with the fact that in previous conversations, some fans told that they themselves are Muslims and are therefore commenting on Sana's hijab from their own experience of being part of the Muslim community in Russia. Although the claim was quickly refuted in a sequence of responses, the discussion that ensued tested the symbolic boundaries of Russia as a multi-confessional and multi-ethnic space. In this debate, for instance, Tatars and socalled "Natives of the Caucasus" are brought up as source of "correct" information on Islam in Russia. At the same time, Islam is treated predominantly as "world religion" on the one hand and as a "personal choice" on the other.

Through these ideas, which also speak to the cultural proximity of the Russophone fan community to the Russian national context, the nation-state of Russia as a geographical space is relocated in a global religious space where Islam, as one of the comments puts it, "can be found". At the same time, when the fans discuss Sana's religious identity, it is almost impossible to push the boundaries of discourse on Islam beyond repetitious comments on the hijab. In almost every comment thread, the discussion continuously jumps back to the hijab and Sana's veiled appearance. Furthermore, the fans do not, for instance, compare Sana's religious practice to the traditions of Orthodox Christianity, such as fasting before Easter and women's use of headscarves in churches, which would offer another framework in which to discuss the meaning of Skam's religious themes in relation to Russia's dominant religion. In consequence, Islam is perceived, overall, rather as a universal religion and a moral code. More precisely, Islam is perceived as a personal choice of the television character Sana, which then becomes an important part of the ideal world of Skam reimagined as the Nordic country Norway.

\section{Conclusion}

The overwhelming popularity outside the national context and fast-expanding online dissemination beyond industry structures prompted my analysis of Skam's online fandom in a Russophone-Norwegian setting of transcultural exchange. I have discussed this case from the point of view of discursive diversity provided by the accumulating multiplicity of cultural resources on online fan community sites. I have argued that these resources can further increase the viewer's competence to contribute to wider geopolitical themes embedded in identity building through popular cultural texts. My analysis has focused 
on how Russophone fans in particular navigate between this multiplicity of semiotic resources and interpretative frameworks.

Analysing the response to the third and fourth seasons of Skam, I found that the core identity issues, LGBTQI+ rights and cultural belonging in Islam, intertwine with fans' perceptions of readily available geopolitical imaginations of Norway and European democracies. However, the fans further develop these imaginations, negotiating between the dominant norms and values of their native context of the "Russophone world" and those supporting the wider global fan community. These negotiations are carried out through a discursive pattern largely based in the repetitive use of previous posts. The most repeated arguments then constitute the core imaginary and become the "highest currency" of these imaginations.

My analysis has demonstrated that the Russophone fans' discursive work around identity is spatially bounded. The spatial dimension of identity building is often activated through the discursive act of relocating compelling representations of identity "elsewhere" from the fans' immediate context. This elsewhere, as it turns out, is both culturally and geopolitically motivated imaginary space. The imaginary realms of popular culture include the worlds of fairy tales and games, as well as the global celebrity cult obsessed by the looks of people seen on screen. At the same time, these spatial imaginations convey a shared understanding of an idealised Nordic space - an imagined Norway - which becomes a desirable, yet mythological place for the fans. The geopolitical position of Norway is further emphasised by creating semiotic links between the geographical space Norway and different cultural images of the "liberal west", such as open manifestations of LGTBQI+. In questions of religious identities, Norway's geopolitical standing becomes more ambiguous and embedded in the ideas of individual choice and personal religious conviction as contrasted with institutionalised ways of religious practice.

All these processes are reflective of the fans' personal desires and emotions, and thus the popular geopolitics of Norden at the background of these forums can best be captured in the paradox of emotional closeness and sociocultural distance between the Russophone context of reception and the Norwegian context of production of global television. The fans find a new home for their personal desires in the Norway reimagined.

The multitude of semiotic registers active in online fan communication requires close reading and analysis of multimodal and, to an extent, multilingual, texts, which is a challenging task, especially in a multidisciplinary setting (such as this special issue). However, tuning in to the "cacophonic" communication style of fan forums adds much needed nuance and depth to our understanding of how individual consumers participate in and contribute to the construction of geopolitical imaginaries. With this case study, I hope to inspire more textual-analytical research on geopolitics and transnational communication in different analytical settings, as well as to engage researchers from literary and cultural studies backgrounds within the popular geopolitics field. A broader focus on different languages or a comparative study between multiple fan cultures would furthermore help create a more comprehensive picture of grass-roots geopolitical imaginations and their role in globalisation, evolving television cultures, and identity construction around the globe. 


\section{Notes}

1. In each season of Skam, written and directed by Julie Andem, the story is narrated through a focal character and the dramatic arc created through the depiction of the main character's battle with a specific life-issue - low self-esteem, lack of trust, sexual identity, and religion. The story is set at Hartvig Nissen high school, which is a real school in a well-to-do neighborhood in central Oslo. Skam was released as a web series, scene-by-scene, and without a set schedule on Norway's National Broadcaster NRK's website, with the story unfolding also through real social media profiles (Facebook, Instagram) of fictional characters. One of the novelties was that the fictional time of the series was fully compatible with the real time of the audience, which produced a highly addictive and immersive media experience (see Krüger \& Rustad, 2019; Bengtsson et al., 2018).

2. Although Skam appeared as a web series and was distributed through online platforms to mobile audiences, I consider it and its fandom against the broader tradition of television culture - especially televisual storytelling - that has its roots in the broadcast era (on the development of web television, see Christian, 2018).

3. Fan fiction stories are not published on the fan profile, but the fans post links to fan fiction sites and quotes from fan fiction stories on the forums. Russophone fans circulate fan fiction written in both Russian and English.

4. On social media use in Russia, see Levada Center, 2019. For more on Russophone online spaces from the perspective of Russia's relations with the neighboring ex-Soviet states, the Russian-speaking diaspora, and Russian linguistic imperialism in the region, see Uffelmann, 2014.

5. Currently, Russia's state paradigm of sexual politics is defined by the federal law banning "propaganda of non-traditional sexuality" among minors, passed in State Duma in 2013. This legislation significantly contributed to Russia's international image as the Eastern European homophobic Other (Baker, 2015). Homophobic discourses have become widespread in Russian domestic media while empowering representations of homosexuality are marginalised from the mainstream circulation. Homophobic and anti-Western sentiments intertwine in the discourse of "geiropa" (gay Europe). This sensationalist media discourse plays an important role in maintaining a symbolic gap between Russia and Western Europe (see Persson, 2015; Hutchings \& Tolz, 2015). Due to the legislation, broadcasting Skam through Russian national networks would be impossible.

6. Here, again the cultural proximity to the Russian context becomes apparent. Muslims are Russia's largest religious minority. Over 10 per cent of the Russian population are Muslims, and Islam is one of Russia's four officially acknowledged "traditional" faiths, together with Orthodox Christianity, Judaism, and Buddhism (Dannreuther \& March, 2010). At the same time, Russia's Muslim population is stigmatised in media and political discourse by associating Islam with separatist radicalism and terrorism in the same way as in public discourses of many Western countries (Hutchings \& Tolz, 2015). This discourse became particularly prominent in the early 2000 s, at the time of the Second Chechen War. Putin effectively appropriated the post-9/11 discourse of Islamic terrorism to consolidate his power during his first term, significantly contributing to Islamophobia, stigmatisation of all Muslims as a potential security threat, and increasing numbers of racist attacks towards the Muslim population of the North Caucasus region (Verkhovsky, 2010; Hunter et al., 2004).

\section{References}

Abdel-Fattah, R. (2005). Does my head look big in this? Sydney: Macmillan Publishers.

Adams, P. (2007). Atlantic reverberations: French representations of an American presidential election. Aldershot: Ashgate. https://doi.org/10.4324/9781351162883

Annett, S. (2014). Anime fan communities: Transcultural flows and frictions. London: Palgrave Macmillan. https://doi.org/10.1057/9781137476104

Baker, C. (2015). Gender and geopolitics in the Eurovision song contest. Contemporary Southeastern Europe, 2(1), 74-93.

\section{Acknowledgements}

I thank the two anonymous reviewers for their insightful comments on my manuscript. I'm grateful to Robert Saunders, Kaarina Aitamurto, Sanna Turoma, participants of Aleksanteri Institute's inhouse seminar, and participants of the international workshop "Nordic Noir, Geopolitics, and the North" at Aarhus University, 4-5 October 2018, for their insightful feedback on the earlier versions of this article. This research was conducted with support from Kone Foundation and University of Helsinki. 
Bengtsson, E., Källquist, R., \& Sveningsson, M. (2018). Combining new and old viewing practices: Uses and experiences of the transmedia series "Skam". Nordicom Review, 39(2), 63-77. https://doi.org/10.2478/ nor-2018-0012

Christian, A. J. (2018). Open TV: Innovation beyond Hollywood and the rise of web television. New York: New York University Press.

Dannreuther, R., \& March, L. (2010). Introduction. In R. Dannreuther, \& L. March (Eds.), Russia and Islam: State, society, and radicalism (pp. 1-8). Abingdon, UK: Routledge. https://doi. org/10.4324/9780203854211

Dittmer, J., \& Dodds, K. (2008). Popular geopolitics past and future: Fandom, identities and audiences. Geopolitics, 13(3), 437-457. https://doi.org/10.1080/14650040802203687

Dittmer, J., \& Gray, N. (2010). Popular geopolitics 2.0: Towards new methodologies of the everyday. Geography Compass, 4(11), 1664-1677. https://doi.org/10.1111/j.1749-8198.2010.00399.x

Dodds, K. (2008). 'Have you seen any good films lately?' Geopolitics, international relations and film. Geography compass, 2(2), 476-494. https://www.doi.org/10.1111/j.1749-8198.2008.00092.x

Fuller, D. (2019). The multimodal reader: Or, how my obsession with NRK's Skam made me think again about readers, reading and digital media. Participations: Journal of Audience and Reception Studies, 16(1), 496-509.

Glathe, J. (2016). Football fan subculture in Russia: Aggressive support, readiness to fight, and far right links. Europe-Asia Studies, 68(9), 1506-1525. https://doi.org/10.1080/09668136.2016.1244260

Glynn, K., \& Cupples, J. (2015). Negotiating and queering US hegemony in TV drama: Popular geopolitics and cultural studies. Gender, Place \& Culture: A Journal of Feminist Geography, 22(2), 271-287. https:// doi.org/10.1080/0966369X.2013.855711

Hellekson, K., \& Busse, K. (2014). Introduction: Why a fan fiction studies reader now? In. K. Hellekdon, \& K. Busse (Eds.), The fan fiction studies reader (pp. 1-17). Iowa City: The University of Iowa Press.

Hunter, S., Melikishvili, A., \& Thomas, J. L. (2004). Islam in Russia: The politics of identity and security. Armonk, New York: ME Sharpe. https://doi.org/10.4324/9781315290133

Hutchings, S., \& Tolz, V. (2015). Nation, ethnicity, and race on Russian television: Mediating post-Soviet difference. Abingdon, UK: Routledge. https://doi.org/10.4324/9781315722863

Krüger, S., \& Rustad, G. C. (2019). Coping with shame in a media-saturated society: Norwegian web-series Skam as transitional object. Television \& New Media, 20(1), 72-95. https://doi. org/10.1177/1527476417741379

Levada Centre. (2019, August 1). Rossiiski medialandshaft 2019 [Russian Media Landscape 2019]. https:// www.levada.ru/2019/08/01/rossijskij-media-landshaft-2019/

Macgregor Wise, J. (2017). Assemblage. In L. Ouellette, \& J. Grey (Eds.), Keywords for media studies (pp. 16-17). New York: New York University Press.

Manovich, L. (2002). The language of new media. Cambridge, Massachusetts: MIT Press.

Naghibi, N., \& O’Malley, A. (2005). Estranging the familiar: "East" and "West” in Satrapi's Persepolis. English Studies in Canada, 31(2), 223-247. https://doi.org/10.1353/esc.2007.0026

O’Halloran, K. L. (2004). Introduction. In K. L. O’Halloran (Ed.), Multi-modal discourse analysis: Systemic functional perspectives (pp. 1-7). New York: Continuum.

Persson, E. (2015). Banning "homosexual propaganda": Belonging and visibility in contemporary Russian media. Sexuality \& Culture, 19(2), 256-274. https://doi.org/10.1007/s12119-014-9254-1

Ratilainen, S. (2019a). Independent and popular? Russian youth videos in the age of globalization. In V. Strukov, \& S. Hudspith (Eds.), Russian culture in the age of globalization (pp. 240-263). Abingdon, UK: Routledge. https://doi.org/10.4324/9781315626628

Ratilainen, S. (2019b, February 28). Russian fans of Norwegian TV series Skam. Nordics.info. http://nordics. info/show/artikel/russian-fans-of-norwegian-tv-series-shame/

Samutina, N. (2013). The care of the self in the 21st century: Sex, love and family in Russian Harry Potter fan fiction. Digital Icons: Studies in Russian, Eurasian, and Central-European New Media, 10, 17-46. https://www.digitalicons.org/wp-content/uploads/issue10/files/2014/01/DI-10-2-Samutina.pdf

Samutina, N. (2016). Fan fiction as world-building: Transformative reception in crossover writing. Continuum, 30(4), 433-450. https://doi.org/10.1080/10304312.2016.1141863

Samutina, N. (2017). Emotional landscapes of reading: Fan fiction in the context of contemporary reading practices. International Journal of Cultural Studies, 20(3), 253-269. https://doi. org/10.1177/1367877916628238

Satrapi, M. (2000). Persepolis. Paris: L'Association.

Saunders, R. A., \& Vessels, J. (2019). Televisual diplomacy: I am the ambassador and Danish nation branding at home and abroad. Politics, 39(4), 430-447. https://doi.org/10.1177/0263395718805403

Schoonover, K., \& Galt, R. (2016). Queer cinema in the world. Durham, North Carolina: Duke University Press. 
Uffelmann, D. (2014). Is there a Russian cyber empire? In M. Gorham, I. Lunde, \& M. Paulsen (Eds.), Digital Russia: The language, culture and politics of new media communication (pp. 266-284). London: Routledge. https://doi.org/10.4324/9781315816470

Varis, P., \& Wang, X. (2011). Superdiversity on the Internet: A case from China. Diversities, 13(2), 71-83. http://www.unesco.org/shs/diversities/vol13/issue2/art5

Verkhovsky, A. (2010). Russian approaches to radicalism and 'extremism' as applied to nationalism and religion. In. R. Dannreuther, \& L. March (Eds.), Russia and Islam: State, society, and radicalism (pp. 26-43). Abingdon, UK: Routledge. https://doi.org/10.4324/9780203854211

Vertovec, S. (2006). The emergence of super-diversity in Britain [Centre on Migration, Policy and Society Working Paper No. 25, University of Oxford, UK]. https://www.compas.ox.ac.uk/wp-content/uploads/ WP-2006-025-Vertovec_Super-Diversity_Britain.pdf

Copyright: (C) 2020 The Author(s) and Nordicom. This is an Open Access article distributed under the terms of the Creative Commons Attribution 4.0 International License (CC BY-NC-ND 4.0). 